\title{
CONSTRUIR EL TERRITORIO DESDE LA ECONOMÍA SOCIAL Y SOLIDARIA Y EL FEMINISMO: PROYECTO "QUÉDATE"
}

\author{
Building the Territory from the Social and Solidarity \\ Economy and Feminism: Project "Quédate" \\ A construção do território a partir da economia social \\ e solidaria e o feminismo: projeto "Quédate»
}

\author{
Marta SOLÓRZANO GARCÍA \\ Universidad Nacional de Educación a Distancia (UNED). Facultad Económicas \\ msolorzano@cee.uned.es \\ Ana Pilar RODRÍGUEZ GUZMÁN \\ Asociación Alzheimer Bierzo (AFA Bierzo). Centro Asociado UNED Ponferrada \\ aprodriguez@ponferrada.uned.es \\ Sara REAL CASTELAO \\ Centro Asociado UNED Ponferrada \\ sarreal@ponferrada.uned.es
}

Fecha de recepción: 14/10/2020

Fecha de aceptación: 8/01/2020

RESUMEN: La despoblación de las zonas rurales en la Comarca de El Bierzo, marcada por el cierre de la minería dibuja un perfil sociodemográfico de población envejecida, cierre de servicios y pérdida de tradiciones y oficios de la zona. Las propuestas de inversión económicas industriales han dejado fuera a estas zonas y han provocado una migración de población en edad activa a entornos urbanos, de manera similar a otras zonas de España. Como alternativa a estos modelos de 
MARTA SOLÓRZANO GARCÍA, ANA PILAR RODRÍGUEZ GUZMÁN Y SARA REAL CASTELAO CONSTRUIR EL TERRITORIO DESDE LA ECONOMÍA SOCIAL Y SOLIDARIA Y EL FEMINISMO: PROYECTO «QUÉDATE»

economía capitalista, existen modelos que promueven el desarrollo territorial, el trabajo en red y ponen en el centro de la economía a las personas, tales como los que promueve la economía social y solidaria. Este modelo comparte con el feminismo postulados que proponen nuevas construcciones sociales del territorio que no excluyan a ninguna persona y que tengan en consideración el medio en el que se desarrollan. Tomando como referencia la zona y estos postulados, se analiza el proyecto "Quédate», proyecto social desarrollado por AFA Bierzo, cuyo objetivo es la mejora de la calidad de vida de personas que viven en entornos rurales, dando respuesta a sus necesidades con una atención integral de servicios que, a su vez, crea empleos para personas que viven en esos ambientes. En sus cinco años de desarrollo, además de conseguir fijar población se ha logrado la atracción a la zona de emprendedoras que ofrecen servicios desde diversas áreas desde la promoción de objetivos de la economía social y solidaria y el feminismo. Se destaca como clave de éxito apostar por estos modelos que ponen en el centro a las personas y su medio y así como contar con alianzas entre las instituciones públicas y asociaciones para poder desarrollar los objetivos y mantenerlos.

Palabras clave: Economía social y solidaria; economía feminista; desarrollo rural; mujer rural; construcción social.

ABSTRACT: Depopulation of rural areas within the region of El Bierzo, specially worsen since mining industry closures, shows a social profile of aging population, loss of services, traditions and crafts. Industrial investments proposed so far, have left out these areas, which made active population moves towards urban environments. As an alternative to this capitalist economic models, there are other ones promoting territorial development and their people, such social and solidarity economics. This model shares postulates with feminism, proposing a new territorial social-based development. This development should be inclusive for everyone and should be aware of the region where it will be applied. The social project "Quédate», developed by AFA Bierzo, is analyzed taking this region and these postulates as a reference. This projects goal is to improve the quality of life of people living in rural environments, taking care of their needs and creating jobs. After five years of development, it has not only been able to retain local population but has also attracted women entrepreneurs who offer very diverse services in multiple areas based in the social, solidarity and feminist economics. It has been key to succeed the use of these models based in the people and their environment. It is also crucial to develop the goals to find alliances between public institutions and associations.

Key words: Social and Solidarity Economy; Feminist Economics; rural development; rural women; social construction.

RESUMO: A despovoamento das zonas rurais da Comarca do El Bierzo, marcado pelo encerramento da mineração, traça um perfil sociodemográfico de uma população envelhecida, encerramento de serviços e perda de tradições e oficios da zona. As propostas de investimento econômico industrial deixaram de fora essas zonas e como consequência surge a migração pela população em idade ativa para 
MARTA SOLÓRZANO GARCÍA, ANA PILAR RODRÍGUEZ GUZMÁN Y SARA REAL CASTELAO CONSTRUIR EL TERRITORIO DESDE LA ECONOMÍA SOCIAL Y SOLIDARIA Y EL FEMINISMO: PROYECTO «QUÉDATE»

o entornos urbanos, semelhande ao ocurrido em outras zonas da Espanha. Como alternativa a estes modelos de economia capitalista, existem modelos que promovem o desenvolvimento territorial tendo como principal objetivo as pessoas, tais como a economia social e solidária. Este modelo partilhia com o feminismo os mesmos principios que promovem novas construções sociais do território sem a exclusão de pessoas, e tendo em consideração o meio em que se desenvolvem. Atendendo a zona e a estes postulados como referência, analisa-se o projeto "Quédate», projeto social desenvolvido por AFA Bierzo, cujo objetivo é melhorar a qualidade de vida das pessoas que vivem no meio rural, respondendo com carinho às suas necessidades serviço abrangente que, por sua vez, cria empregos para as pessoas que vivem nos entornos rurais dando resposta às suas necessidades com uma aten ção integral que, por sua vez, geram empregos para as pessoas que vivem nesses ambientes. Nos seus cinco anos de desenvolvimento, além de fixar a população, tambén a zona demostrou ser un atrativo por parte de emprendedoras que oferecem serviços de diversas áreas desde a promoção dos objetivos da economia social e solidária e do feminismo. Destaca-se como foco principal de êxito a aposta por estes modelos que tem como objetivo as pessoas e o seu meio no centro, bem como contar com alianças entre instituições públicas e associações para poder desenvolver os objetivos e mantê-los.

Palavras chave: Economia Social e Solidária; Economia Feminista; desenvolvimento rural; mulher rural; construção social.

\section{INTRODUCCIÓN}

La globalización económica, iniciada en el siglo XX y consolidada en todos los ámbitos en las dos primeras décadas del siglo XXI, pone de relieve cifras que destacan el desarrollo económico, tecnológico, político y social. Estos datos, que devienen de indicadores o medias estadísticas, homogeneizan una realidad y destacan contextos urbanos y masculinizados. Las otras realidades, las que se descubren en los análisis de casos o en las revisiones pormenorizadas de datos que tienen en cuenta las desviaciones de esas medias, son, en muchos contextos, realidades rurales heterogéneas dentro en un mismo territorio y con una marcada identidad, como sucede en la provincia de León. Una provincia eminentemente rural, con solo seis municipios que superan los 10.000 habitantes, una población envejecida y bajas tasas de natalidad (INE, 2020a).

La fuerte transición demográfica de los años 50, el "éxodo rural», que conllevó a la despoblación de los entornos rurales y la nueva ordenación territorial y social en gran parte del territorio español, no se desarrolló de la misma manera en territorios como las cuencas mineras de las zonas de León. Mientras el resto de España migraba a las ciudades, estas zonas tenían tasas de crecimiento positivo gracias a la actividad extractiva del carbón que generaba una red de sostenimiento económico que fijaba población y resistía al envejecimiento sociodemográfico. Zonas mineras como las de la de León y Palencia tuvieron un importante incremento de 
MARTA SOLÓRZANO GARCÍA, ANA PILAR RODRÍGUEZ GUZMÁN Y SARA REAL CASTELAO CONSTRUIR EL TERRITORIO DESDE LA ECONOMÍA SOCIAL Y SOLIDARIA Y EL FEMINISMO: PROYECTO «QUÉDATE»

población en la primera mitad del siglo XX y mantuvieron índices positivos de crecimiento hasta finales del siglo pasado (Caballero Fernández-Rufete, Delgado Urrecho y Martínez Fernández, 2012). Estos municipios formados por núcleos rurales recibieron población de otras zonas del país y de otros países para dar respuesta a la intensa actividad minera de la zona. Cabe apuntar que este sector económico claramente masculinizado ha sido, en muchas zonas, fuente única de ingresos y de actividad por la solvencia que las condiciones de este trabajo suponían a las familias.

Esta descripción sociodemográficamente positiva, de sociedades rurales mineras en las que un sector masculinizado era la principal fuente de ingresos y que ha fijado población en un momento, finales del s. XX, en el que otras zonas rurales de España ya estaban vacías, también ha conllevado al cese de oficios tradicionales (sector textil, ganadero, lácteo, agrícola, herrería, etc.) como medio de vida. Algunas de ellas, como las ganaderas y agrícolas, se han mantenido para el autoconsumo en el ámbito privado, desapareciendo de las cifras oficiales e invisibilizándose su presencia y registro.

En el mejor de los casos, estas actividades de mantenimiento han sido desarrolladas por mujeres que permanecían en el territorio rural, puesto que los hombres estaban en gran parte dedicados al sector de la minería. Estos trabajos no figuran en las estadísticas sobre tasas de actividad, no generan cotizaciones, ni derechos laborales, aunque sí han supuesto una fuente de ahorro para las familias y una perpetuación de estos oficios en estas zonas. En otros casos, los oficios no se han mantenido y se ha roto la cadena de transmisión generacional de aprendizaje informal (por no estar reglado), que actualmente solo pervive en la memoria de las personas de mayor edad de estos entornos y presenta un alto riesgo de desaparecer ante la falta de continuidad familiar o mentoría en nuevas iniciativas. Esta situación de preeminencia del sector minero que fijaba la población de las zonas mineras y mantenía económicamente a zonas limítrofes, comenzó a tener un efecto menos marcado a partir de la década de los años 70, acabando con una grave crisis a inicios del siglo XXI hasta su cierre total en el año 2018.

Es a partir de finales de los años 90, y con un mayor descenso en la primera década del siglo XXI, cuando estas zonas han perdido población y se "han vaciado" como otras tantas zonas de España, aunque en un momento social de crisis económica general y con una sociedad global que ya había dejado fuera de su discurso a las identidades rurales (Díaz Mendez, 2005). Así, se pasa de contar con zonas rurales en las que había una clara masculinización y una población en edad activa (Camarero y Sampedro, 2008) a una realidad con mayor presencia de mujeres y con una población marcadamente envejecida (INE, 2020a). En este proceso de cambio laboral, social y demográfico, las mujeres de las zonas rurales, que tenían una identidad minera derivada de los hombres de su entorno, pero de la que no son protagonistas, se quedan fuera de los movimientos sociales urbanos y, por ende, de los movimientos feministas, que estaban marcadamente urbanizados, además de sin derechos laborales adquiridos en primera persona 
MARTA SOLÓRZANO GARCÍA, ANA PILAR RODRÍGUEZ GUZMÁN Y SARA REAL CASTELAO CONSTRUIR EL TERRITORIO DESDE LA ECONOMÍA SOCIAL Y SOLIDARIA Y EL FEMINISMO: PROYECTO «QUÉDATE"

por no haber contado con empleos, sino con trabajo no remunerado (productivo y reproductivo).

Cabe apuntar que en la década de los años 90 ya se desarrollaron iniciativas comunitarias desde la Unión Europea en las que se pretendía apoyar al mundo rural mediante la creación de empleos que lograran fijar la población y conseguir un desarrollo sostenible de estas zonas, los conocidos programas LEADER, LEADER II o PRODER. Sin embargo, para las zonas rurales descritas, estos programas se implantaron cuando todavía no había una conciencia clara de necesidad de alternativas al sector minero en la población. Estos programas han sido ampliamente analizados en diversos contextos del territorio con conclusiones de impacto positivo respecto a la diversificación de actividades en las zonas rurales y las inversiones realizadas (Carmona García, 2013; Nieto Masot, Gurria Gascón, 2010; Sánchez Muñoz, 1999; Verdugo Matés, Pérez Fra y López Iglesias, 2004). En la provincia de León, y en concreto en las zonas de la Comarca de El Bierzo, las principales actividades desarrolladas bajo estos programas se centraron en el turismo rural mediante inversiones individuales, o en mejoras de la conservación y del medio ambiente mediante inversiones públicas (Sánchez Muñoz, 1999). Estas iniciativas, aunque han sido importantes para la zona, no han podido amortiguar el efecto de la despoblación provocado por el cierre del sector minero del carbón.

\section{El CUIDADO DE lOS TERRITORIOS: ECONOMÍA SOCIAL Y SOLIDARIA Y ECONOMÍA FEMINISTA}

Teniendo en cuenta estos antecedentes, la actualidad de las zonas rurales mineras y las zonas adyacentes que han sido afectadas por este cese de actividad, presentan una marcada y reciente despoblación que requiere de modelos de emprendimiento que respondan a un desarrollo del territorio desde una construcción que tenga en cuenta a todas las personas que en él viven (sin excepción) y que parta de un modelo organizativo acorde a los objetivos de desarrollo de la agenda 2030.

Históricamente, han sido numerosas las iniciativas que, desde enfoques plurales, han dado respuesta a los problemas sociales existentes, reconociéndose con otra forma de entender y hacer economía desde criterios relacionados con la justicia social. Una parte importante de estas experiencias, reconocidas como Economía Social, se ha construido sobre los principios de la primacía de la persona y el objeto social sobre el capital, la adhesión voluntaria y abierta, el control democrático por sus miembros, la conjunción entre los intereses de sus miembros y el interés general, la defensa y aplicación de los principios solidaridad y responsabilidad, la autonomía de gestión e independencia frente a los poderes públicos, así como el destino de la mayoría de sus excedentes a la consecución de objetivos a favor del desarrollo sostenible, del interés de los servicios a los miembros y del interés general (CEP-CMAF, 2002). 
MARTA SOLÓRZANO GARCÍA, ANA PILAR RODRÍGUEZ GUZMÁN Y SARA REAL CASTELAO CONSTRUIR EL TERRITORIO DESDE LA ECONOMÍA SOCIAL Y SOLIDARIA Y EL FEMINISMO: PROYECTO «QUÉDATE»

Todas estas experiencias han ido configurando un modo de ser empresa con valores y prácticas diferenciadas. En definitiva, el término de Economía Social engloba al grupo de entidades privadas que han sido creadas por sus miembros para la satisfacción de sus necesidades a través del mercado; cuyo funcionamiento está basado en principios distintos al de maximización de beneficios, tales como la priorización de las personas sobre el capital o la toma de decisiones de forma democrática; y que se rigen por valores como la solidaridad y el compromiso con el entorno (Monzón y Chaves, 2012).

Del desarrollo histórico de la Economía Social surge la Economía Solidaria como como una alternativa a la economía de capital, que persigue construir relaciones de producción, distribución, consumo y financiación basadas en la justicia, cooperación, reciprocidad y ayuda mutua; poniendo a las persona y su trabajo en el centro del sistema económico y otorgando a los mercados un papel instrumental al servicio del bienestar de todas las personas, llegando a denominarse un "proyecto ético de vida" (Da Ros, 2007). Esta perspectiva confiere a la Economía Social y Solidaria una intención fundamentalmente transformadora, que se desarrolla a través de prácticas relacionadas con el empoderamiento de las personas, el impulso de relaciones basadas en la cooperación, el desarrollo de modelos democráticos en la toma de decisiones, la conservación ecológica, la igualdad de oportunidades, la valoración de los procesos relacionados con la reproducción de la vida y con los cuidados, la generación de riqueza e instrumentos financieros en condiciones éticas, el refuerzo de las capacidades de personas y colectivos especialmente excluidos, la innovación socioeconómica al servicio del desarrollo humano local, etc. (Rey y Cía, 2007).

De los autores relacionados con este enfoque se distinguen tres dimensiones complementarias (Coraggio, 2011; Guerra, 2013, 2011; Martínez y Álvarez, 2008): la dimensión teórica, que pretende establecer un nuevo paradigma alternativo sobre la economía; la dimensión política de transformación social hacia un modelo socioeconómico basado en formas de sociabilidad no capitalista; y la dimensión económica, relacionada con un tipo específico de organización basada en la democracia, la autogestión y el empresariado colectivo (Pérez de Mendiguren y Etxezarreta, 2015). En este sentido, las prácticas, el alcance y el impacto que genera la economía social y solidaria recuperan la visibilidad de la interrelación entre las esferas política, económica y social y por esta razón, desde la perspectiva feminista, se defiende la idea de que la economía social y el feminismo deberían trabajar unidos para reconstruir un sistema alejado del capitalista (Osorio Cabrera, 2014). Este sistema, además, no excluye al mundo rural, sino todo lo contrario, para gran parte de las iniciativas en las que se prima el bienestar de las personas que participan en ella, el entorno rural es un medio que favorece más la implantación que los ámbitos urbanos en los que las inversiones de partida, la flexibilidad, y la conciliación con otras esferas de la vida presenta más dificultades o es inalcanzable.

Así pues, el feminismo busca equiparar a las mujeres y hombres en la esfera socioeconómica, en la política y en los procesos de toma de decisiones. La 
MARTA SOLÓRZANO GARCÍA, ANA PILAR RODRÍGUEZ GUZMÁN Y SARA REAL CASTELAO CONSTRUIR EL TERRITORIO DESDE LA ECONOMÍA SOCIAL Y SOLIDARIA Y EL FEMINISMO: PROYECTO «QUÉDATE»

economía feminista, en particular, plantea una alternativa al capitalismo y las crisis económicas, climáticas y sociales que este sistema genera, intenciones coincidentes con las de la economía social y solidaria en su propuesta de modelo organizativo (Matthaei, 2010).

Partiendo de estos presupuestos comunes, el análisis a realizar en este trabajo analiza los siguientes objetivos que comparten la economía social y solidaria y el feminismo (Matthaei, 2010).

- Dar respuesta a las necesidades bumanas.

- Reconstruir nuevas jerarquías económicas en las que no se excluyan a grupos sociales ni se apliquen prácticas opresivas.

- Innovación y transformación social.

- Protección y conservación de las comunidades y del medio ambiente.

Cabe destacar que estos postulados son claves en ambos modelos y no solo características de interrelación, por lo que se considera que uno de los pilares sobre los que se construye la economía social y solidaria es el feminismo. Además del postulado común en los modelos descritos, la Agenda 2030 redactada por la Organización de las Naciones Unidas (ONU) en 2015 y compuesta por 17 objetivos de desarrollo sostenible (ODS), contempla en su quinto objetivo la igualdad de género. Entre los objetivos y sus metas, la ONU destaca 6 soluciones emblemáticas para lograr en el horizonte de una década: mantener a las personas fuera de la pobreza, modelos de gobernanza para forjar sociedades pacíficas, justas e inclusivas, prevención de las crisis y mayor resiliencia; soluciones basadas en la naturaleza para el desarrollo; energía no contaminante y asequible y, por último, el empoderamiento de la mujer e igualdad de género ${ }^{1}$.

Estas 6 soluciones o logros emblemáticos son la base de la economía social y solidaria y del feminismo, por lo que el desarrollo de iniciativas bajo estos modelos debe ser apoyado por todos los gobiernos e instituciones que se han comprometido en el desarrollo de los objetivos de desarrollo sostenible.

En lo que respecta al cumplimiento de las metas planteadas por el objetivo quinto de la igualdad de género, uno de los aspectos en los que España todavía está lejos poder hablar de igualdad es en la representación de mujeres en cargos directivos en empresas e instituciones y en la proporción de tiempo dedicada al trabajo doméstico y asistencial no remunerado (INE, 2020b) A pesar de los avances legales y sociales, la desigualdad y las prácticas discriminatorias se reproducen tanto dentro como fuera de la organización empresarial.

Tanto la economía social como el feminismo defienden la necesidad de establecer un nuevo sistema de bienestar social, más justo y sostenible, centrado en las personas (Larrañaga; Jubeto y Diez, 2015). Para combatir la desigualdad

1. https://www.undp.org/content/undp/es/home/six-signature-solutions.html 
MARTA SOLÓRZANO GARCÍA, ANA PILAR RODRÍGUEZ GUZMÁN Y SARA REAL CASTELAO CONSTRUIR EL TERRITORIO DESDE LA ECONOMÍA SOCIAL Y SOLIDARIA Y EL FEMINISMO: PROYECTO «QUÉDATE"

de género, la economía social crea las posibilidades para eliminar las barreras y asimetrías en las condiciones laborales. Además, ofrece espacios de actuación personal y de autogestión que proporcionan una conciencia social, de forma que las mujeres son agentes reconocidas en la esfera social, económica y política y al contar con una participación activa en espacios democráticos de cooperación, consiguen el reconocimiento de los derechos de los que antes carecían (Hoinle, Rothfuss y Gotto, 2013).

Una realidad que aboga por la visibilización de la mujer como sujeto político, económico y social son las empresas sociales, cuyos principios se basan en los de la economía social y solidaria y la economía feminista. Existen numerosas experiencias de empresas sociales a nivel mundial, aunque su presencia en el mercado es reducida si se compara con la de las empresas capitalistas. No obstante, cada vez son más las empresas que se enmarcan en un nuevo escenario socio económico que promueva un bienestar colectivo basado en los principios de la economía social y feminista: equidad, corresponsabilidad, democracia económica y reciprocidad (Larrañaga; Jubeto y Diez, 2015), como alternativa al desarrollo industrial urbanizado que no ha sido capaz de impulsar a estos territorios, conllevando a su marginación (Calatrava-Requena, 1997).

Los valores sobre los que se construyen las empresas de la economía social y solidaria se caracterizan por perseguir la igualdad real de las mujeres (Senent Vidal, 2011). Cabe destacar que la mayoría de las personas que trabajan en la economía social a nivel mundial son mujeres que fueron excluidas por el capitalismo (Matthaei, 2010). En este sentido, no es de extrañar que el perfil laboral de las mujeres se ajuste más a la filosofía de las empresas sociales. Esto se debe a que las mujeres prefieren un ambiente de trabajo participativo, democrático y solidario, características que presenta la organización estructural de las empresas sociales. Además, las mujeres encuentran ventajas en el hecho de participar en una empresa social como un entorno empresarial donde desarrollar su carrera profesional o la posibilidad de influir y mejorar el entorno (Ribas y Sajardo, 2005).

Partiendo de la realidad sociodemográfica e identitaria comentada en la zona de la Comarca de El Bierzo y siguiendo los principios de la economía social y solidaria y el feminismo se analiza en el siguiente apartado un proyecto de desarrollo territorial que parte de una iniciativa social y cuyo objetivo es la fijación de población como punto de partida para una construcción del territorio que promueva tanto una economía social y solidaria como una sociedad feminista.

\section{ANÁlisis DEL PROYECTO «QuÉDATE» DE AFA BIERZO}

El proyecto "Quédate» se desarrolla dentro de La Asociación AFA Bierzo. Esta asociación fue creada en 1998 por familiares de personas con Alzheimer en la Comarca de El Bierzo, con la idea de crear recursos que dieran respuesta a estas personas afectadas por la enfermedad y para sensibilizar y formar a la sociedad en 
MARTA SOLÓRZANO GARCÍA, ANA PILAR RODRÍGUEZ GUZMÁN Y SARA REAL CASTELAO CONSTRUIR EL TERRITORIO DESDE LA ECONOMÍA SOCIAL Y SOLIDARIA Y EL FEMINISMO: PROYECTO «QUÉDATE»

general sobre esta problemática ${ }^{2}$. Su importancia en el territorio como respuesta a las necesidades de las familias tuvo su reconocimiento en mayo de 2009, momento en el que el Ministerio del Interior la declaró Entidad de Utilidad Pública (BOE, 2009, N. ${ }^{\circ}$ 109).

Esta entidad, además, ha creado redes de colaboración formando parte del programa nacional de "Mirada Rural» junto con otras entidades con las que comparte misión y visión y como entidad adherida a la Cátedra de Turismo Sostenible y Desarrollo Local de la UNED, con el fin de sumar apoyos y crear espacios de gobernanza institucional que permitan impulsar los proyectos de desarrollo territorial.

Dentro de los proyectos que se desarrollan en la entidad, se destaca por la temática de este trabajo, y la promoción de modelos de la economía social y solidaria y el feminismo, el proyecto "Quédate», proyecto iniciado en el año 2015 y cuyo objetivo es mejorar la calidad de vida de las personas residentes en el medio rural berciano, mediante la detección de necesidades sociales, sanitarias, funcionales y psicológicas de las personas residentes en zonas rurales de El Bierzo y la respuesta a estas de manera integral.

Además de esta detección y respuesta general, se identifica a aquellas personas que pudieran ser susceptibles de estar padeciendo un deterioro cognitivo o demencia, de tal forma que puedan iniciar lo antes posible un tratamiento farmacológico y no farmacológico que ralentice los síntomas y aminore los cambios que produce la enfermedad; así como favorecer la posibilidad de prevenir las enfermedades o trastornos que la originan ${ }^{3}$.

Con este Proyecto, por tanto, AFA Bierzo proporciona una atención integral a aquellas personas que lo necesiten, posibilitando que permanezcan en sus domicilios. Con esta iniciativa se persigue, además de evitar que las personas mayores tengan que abandonar sus entornos a los que se encuentran arraigados, que personas jóvenes en situación de desempleo puedan ofrecer estos servicios y así poder mantenerse en el territorio sin necesidad de ir a trabajar a entornos urbanos si así lo deciden.

Este objetivo general, se concreta en cinco objetivos específicos, a saber:

Estudiar la situación, necesidades y demandas de las personas residentes en las localidades rurales en las que se realiza la intervención para realizar un diagnóstico social.

- Prevenir la dependencia de las personas residentes en el medio rural, potenciando la maduración saludable, advirtiendo y/o retrasando el inicio y/o avance de una posible demencia en las personas beneficiarias del Proyecto.

2. http://afabierzo.org/

3. http://afabierzo.org/blog/2019/03/11/891/ 
MARTA SOLÓRZANO GARCÍA, ANA PILAR RODRÍGUEZ GUZMÁN Y SARA REAL CASTELAO CONSTRUIR EL TERRITORIO DESDE LA ECONOMÍA SOCIAL Y SOLIDARIA Y EL FEMINISMO: PROYECTO «QUÉDATE»

- Realizar intervenciones globales tendentes a estimular y mantener las capacidades mentales, así como a obtener un mejor rendimiento cognitivo y una mayor autonomía personal e intervenciones individuales en aquellos casos que requieran una atención especializada y personal por encontrase en riesgo de vulnerabilidad social.

- Mantener a las personas residiendo en sus domicilios con una buena calidad de vida, aprovechando los recursos socio-comunitarios existentes en cada localidad de intervención.

- Conservar y transmitir el patrimonio inmaterial de las localidades de intervención mediante el registro, publicación y difusión de relatos de las personas de estos entornos.

En todas las acciones encaminadas a la consecución de estos objetivos realizadas por el personal responsable del proyecto, se tienen en cuenta los principios de independencia, participación, dignidad, asistencia y realización, además de alinearse con todos los ODS planteados en la Agenda 2030 (ONU, 2015) que se ha comentado en el apartado previo. Para ello incluyen en sus intervenciones nuevas esferas como el cambio climático, la desigualdad económica, la innovación, el consumo sostenible, la paz y la justicia, o la igualdad de género entre otras prioridades.

Actualmente el proyecto cuenta con 18 mujeres profesionales de distintas áreas que están dedicadas parcial o totalmente a este proyecto desde la entidad AFA Bierzo, tal y como se refleja en la tabla 1, generando oportunidades de empleo en el territorio. Cabe apuntar que en la selección de personal para trabajar en el proyecto no se indicaba ninguna preferencia en género, sin embargo, en el área sociosanitaria, el perfil predominante es el de las mujeres, hecho que habrá conllevado a que el 100\% de las trabajadoras lo sean. Además de estas profesionales, el proyecto cuenta con el trabajo de trabajadores de CEAS y de Centros de Salud que apoyan con su labor en las oficinas itinerantes. 
MARTA SOLÓRZANO GARCÍA, ANA PILAR RODRÍGUEZ GUZMÁN Y SARA REAL CASTELAO CONSTRUIR EL TERRITORIO DESDE LA ECONOMÍA SOCIAL Y SOLIDARIA Y EL FEMINISMO: PROYECTO «QUÉDATE»

TABla 1. PERFILES PROFESIONALES QUE DESEMPEÑAN SU LABOR EN EL PROYECTO DESDE LA ENTIDAD AFA BIERZO

\begin{tabular}{|c|c|}
\hline $\begin{array}{l}\text { PERFILES DE PERSONAS QUE TRABAJAN } \\
\text { EN EL PROYECTO }\end{array}$ & $\begin{array}{l}\text { N. }{ }^{\circ} \text { DE HORAS SEMANALES DEDICADAS } \\
\text { AL PROYECTO POR CADA PERSONA }\end{array}$ \\
\hline 1. Directora & 10 \\
\hline 1. Psicóloga & 20 \\
\hline 1. Trabajadora Social & 20 \\
\hline 1. Terapeuta ocupacional & 20 \\
\hline 1. Fisioterapeuta & 20 \\
\hline 1. Socióloga & 40 \\
\hline 1. Abogada & 40 \\
\hline 1. Musicoterapeuta & 40 \\
\hline 1. Administrativa & 10 \\
\hline $\begin{array}{l}\text { 2. Técnicas en actividades de Animación } \\
\text { sociocultural (TASOC) }\end{array}$ & 40 \\
\hline 1. TASOC- apoyo & 8 \\
\hline $\begin{array}{l}\text { 3. Técnicas en cuidados auxiliares en } \\
\text { enfermería (TCAE) }\end{array}$ & 120 \\
\hline 2. Asistentas personales & 20 \\
\hline
\end{tabular}

Además de la fijación de la población en estos entornos con las personas destinatarias y trabajadoras, lograda mediante los objetivos específicos comentados, el proyecto en su fase de consolidación se plantea propiciar la presencia de nuevas personas pobladoras en los lugares de intervención que ofrezcan servicios a las personas que permanecen en estos territorios, mediante estrategias de difusión, formación y asesoramiento.

Estos objetivos se han desarrollado en 17 localidades del entorno rural ${ }^{4}$ ubicadas en 4 zonas de la Comarca de El Bierzo, en colaboración con los ayuntamientos

4. Detalle de las zonas en las que se desarrolla el proyecto Zona Bierzo Oeste: Corullón y Villafranca del Bierzo.

- Zona Bierzo Central: Cubillos del Sil, Fresnedo, Toral de los Vados, Arganza y Cortiguera.

- Zona Ancares-Sil: Vega de Espinareda, Matarrosa del Sil, Toreno, Páramo del Sil, Fabero, Lillo del Bierzo, Berlanga del Bierzo y San Pedro de Olleros.

- Zona Bierzo Alto: Bembibre y Santa Marina de Torre. 
MARTA SOLÓRZANO GARCÍA, ANA PILAR RODRÍGUEZ GUZMÁN Y SARA REAL CASTELAO CONSTRUIR EL TERRITORIO DESDE LA ECONOMÍA SOCIAL Y SOLIDARIA Y EL FEMINISMO: PROYECTO «QUÉDATE»

de esas localidades y, en especial, con los Centros de Acción Social (CEAS) dependientes de la Diputación de León. Actualmente el proyecto está atendiendo directamente a 845 personas que presentan una situación de necesidad o vulnerabilidad social y que forman una red de 1690 familiares directos. Las personas contratadas en el proyecto son en su mayoría mujeres ya que son estas las que cuentan con formación y experiencia en atención sociosanitaria y por tanto cumplen los requisitos de acceso a los puestos de trabajo.

La consecución de los citados objetivos se concreta en 12 actuaciones de diversas áreas, que se describen a continuación y que dan idea de la complejidad del presente proyecto:

1. Dar visibilidad al proyecto: dentro de esta primera actuación, desde la entidad promotora, AFA Bierzo, se difunde el proyecto entre los Agentes Sociales y las Administraciones donde se desarrolla. Para tal fin se ha creado una comisión de seguimiento en cada localidad del medio rural destinataria, formada por dos representantes del Equipo Multidisciplinar de AFA Bierzo que participa en el Proyecto, dos representantes de la Entidad Local objeto de intervención y dos representantes de los agentes sociales de la zona (asociaciones de pensionistas, profesionales sanitarios, CEAS, etc.). Estas comisiones multidisciplinares y con representación de los agentes clave del territorio y profesionales, son un elemento clave y vertebrador de todo el proyecto. En la figura 1se muestra uno de los carteles con los que la Entidad AFA Bierzo ha dado difusión al proyecto.

2. Diagnóstico Social: desde la entidad promotora, AFA Bierzo, elabora un diagnóstico social, mediante la recolección de datos y la información de las personas que viven en el territorio y que forman parte de la comisión, para poder conocer las necesidades de las personas residentes en los 17 lugares de intervención. Cabe destacar la importancia del diagnóstico partiendo de la información de personas del territorio, por la falta de microdatos en los portales estadísticos generales de perfiles sociodemográficos de localidades concretas y por la inmediatez de ocurrencia y necesidad de respuesta de las situaciones ante las que el proyecto pretende intervenir. Estas situaciones, como pueden ser situaciones de soledad o aislamiento o casos de síntomas leves de demencia, no cuentan con registros en sistemas oficiales de recolección de datos o informes sanitarios derivados del sistema de salud primario u hospitalario, y para su recogimiento y diagnóstico se requiere implicar a personas del territorio. 


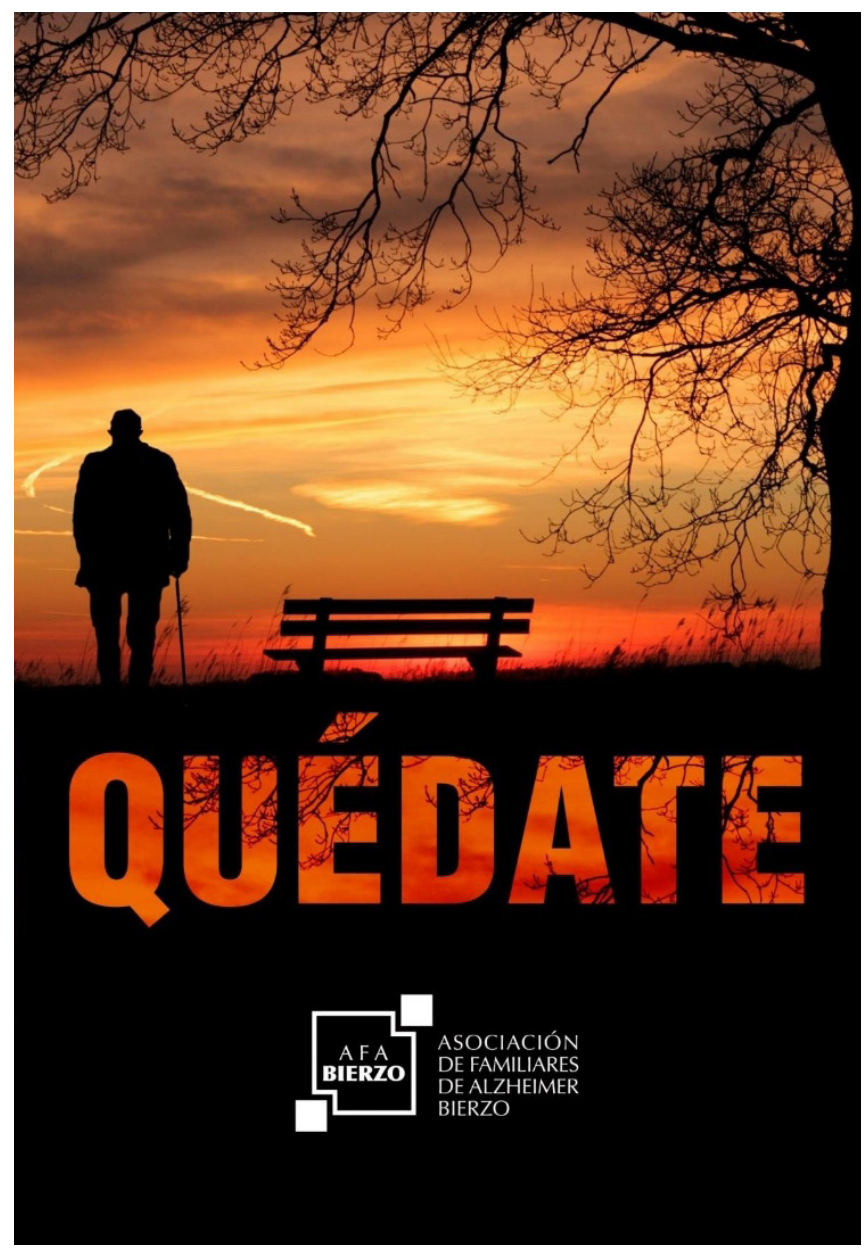

Figura n. ${ }^{\circ}$ 1. Cartel de presentación y difusión del proyecto Quédate realizado por AFA bierzo.

3. Creación de un catálogo de servicios local: con el fin de difundir y visibilizar las oportunidades que ofrecen cada una de las 17 localidades, una actuación planteada es la creación de un catálogo de servicios multidisciplinar que ayude a fijar e incrementar población en zonas rurales siendo viable, sostenible y escalable. Este catálogo es elaborado en las oficinas itinerantes como respuesta a las necesidades surgidas en el diagnóstico social. 
MARTA SOLÓRZANO GARCÍA, ANA PILAR RODRÍGUEZ GUZMÁN Y SARA REAL CASTELAO

CONSTRUIR EL TERRITORIO DESDE LA ECONOMÍA SOCIAL Y SOLIDARIA Y EL FEMINISMO: PROYECTO «QUÉDATE»

4. Aulas de formación Preventivas: mediante los talleres impartidos en estas aulas formativas se realizan sesiones grupales de cognición, socioculturales y recreativos, dirigidos a personas residentes y con el objetivo de prevenir el deterioro cognitivo, el aislamiento y soledad. Estas sesiones se realizan una vez a la semana en cada una de las localidades donde se lleva a cabo el proyecto. Además del objetivo preventivo por la acción formativa en sí misma, estos talleres son utilizados por los profesionales de la entidad como herramienta de detección de casos de vulnerabilidad y conocimiento de la población beneficiaria; a la vez que se les proporciona a los asistentes conocimientos sobre cuidados básicos, asesoramiento en hábitos de vida saludables, estimulación cognitiva (atención, memoria y lenguaje), alimentación equilibrada, prevención de caídas, accidentes en el domicilio, duelo, adaptación a los cambios sociales y familiares e inteligencia emocional, entre otros. La figura 2 muestra una fotografía tomada en una de las aulas de acción preventiva en la que se observa la interacción entre profesionales y usuaria.

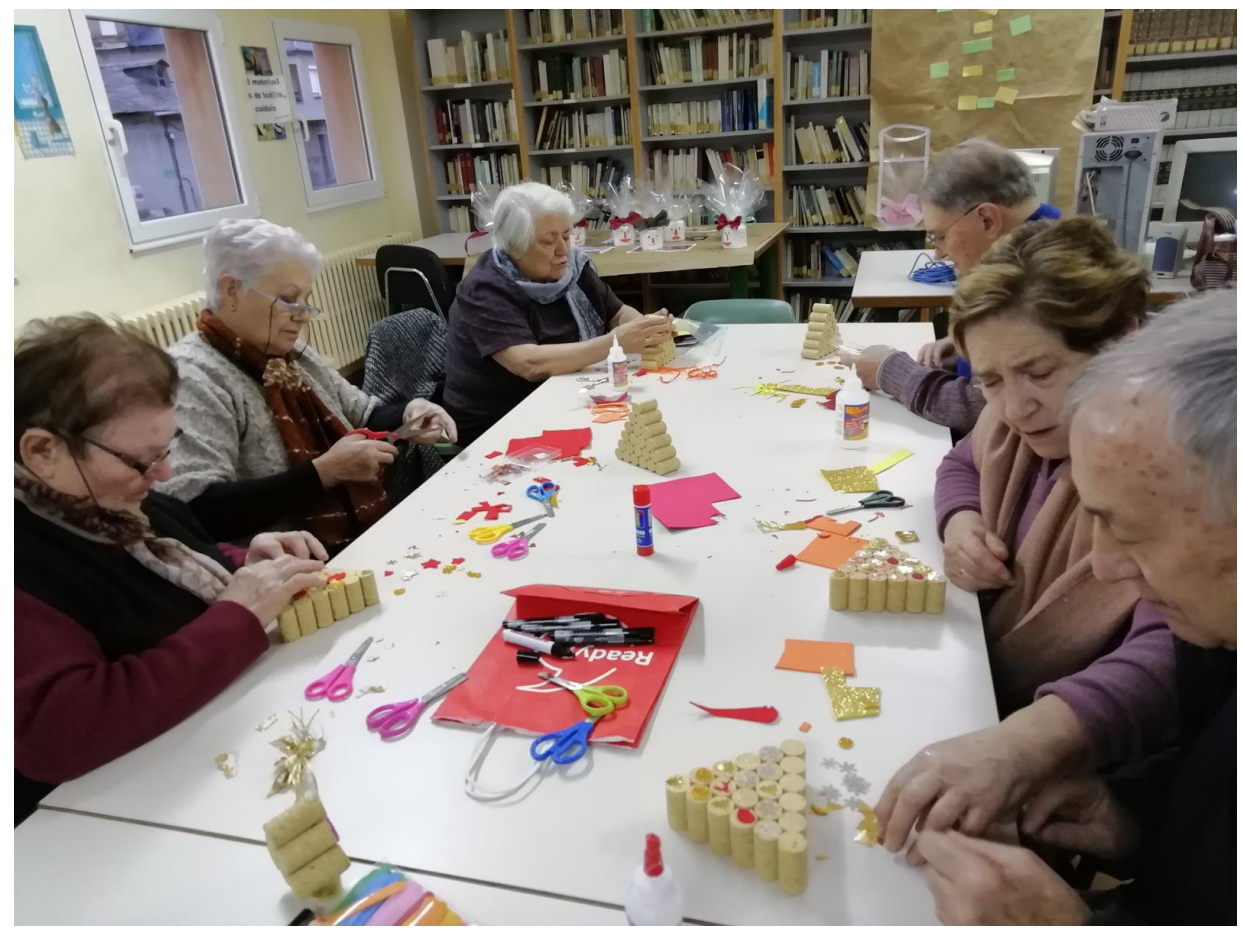

Figura n. ${ }^{\circ}$ 2. Fotografía de un taller realizado dentro de las Aulas de formación preventivas. 
Dentro de las temáticas de los talleres, cuyo fin es mantener la mente activa, respetando y mejorando la historia y proyecto de vida de las personas beneficiarias se trabajan temas claves como la igualdad de género en la sociedad, en consonancia con los principios del movimiento feminista y como aporte a la consecución de metas del objetivo 5 de los ODS ya comentado, siendo este un objetivo que se trata de manera transversal en todos los talleres y como objetivo de contenido en otros en los que específicamente se abordan conceptos sobre feminismo y las implicaciones sociales y personales de la falta de consecución de estos derechos. La figura 3 muestra una imagen de un taller en el que se ha abordado la igualdad de género como contenido con la población beneficiaria.

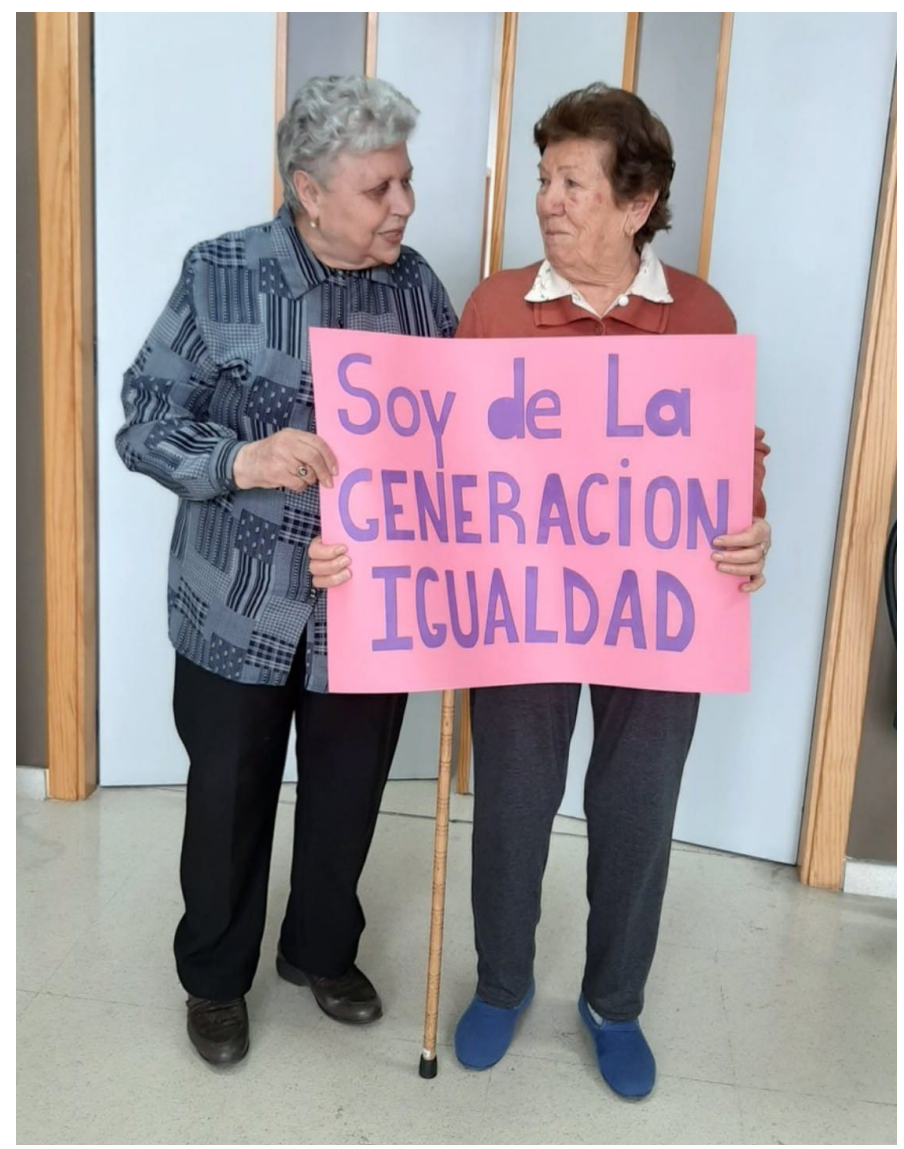

Figura n. ${ }^{\circ}$ 3. Fotografía de taller de formación preventiva en el que se han trabajado la temática de igualdad de género y sus implicaciones. 
MARTA SOLÓRZANO GARCÍA, ANA PILAR RODRÍGUEZ GUZMÁN Y SARA REAL CASTELAO CONSTRUIR EL TERRITORIO DESDE LA ECONOMÍA SOCIAL Y SOLIDARIA Y EL FEMINISMO: PROYECTO «QUÉDATE»

5. Registro de situaciones de vulnerabilidad: tal y como se indica en las actuaciones anteriores, uno de los objetivos de los talleres es la detección de situaciones de vulnerabilidad entre la población residente que acude a los talleres. Con los casos detectados se elabora un registro de las personas asistentes a estas aulas de formación preventivas que se encuentran en situación de posible vulnerabilidad, ya sea ocasionado por un factor de riesgo como es la edad avanzada, por una posible demencia u otras causas.

6. Intervención profesional domiciliaria y en el entorno: En el caso de personas que presenten situaciones de necesidad, vulnerabilidad o aislamiento, que hayan sido detectadas en el diagnóstico social o mediante el registro de situaciones de vulnerabilidad descrito anteriormente, se realizan intervenciones individuales y específicas que den respuesta a estas necesidades en su entorno.

Este servicio se ha mantenido durante la situación de confinamiento determinada por el estado de alarma decretado el 14 de marzo de 2020 (BOE, 2020, N. ${ }^{\circ}$ 67), incluyendo en la intervención domiciliaria la entrega de actividades que en la situación previa se hacían en los talleres presenciales de formación preventiva. Esta continuidad del proyecto se ha podido realizar gracias a la colaboración de los ayuntamientos, y de 50 personas voluntarias que cada día realizaban una media de 100 llamadas y videollamadas a las personas beneficiarias del programa, en estas llamadas además de comprobar el estado de las personas y así evitar el aislamiento y soledad, se hacía un seguimiento de las actividades entregadas por el personal de protección civil de cada localidad. En la fotografía 4 se muestra una entrega de un cuadernillo de actividades a una de las beneficiarias del proyecto.

7. Servicio de compra a domicilio: una de las actuaciones que se han visto como claves dados los problemas de movilidad de las personas de edad avanzada y la falta de servicios de alimentación en el entorno rural son las compras a domicilios, con esta acción se tiene previsto facilitar la provisión semanal y dispensación de productos de primera necesidad con entrega en cada domicilio, a la vez que se aconseja y supervisa sobre nutrición e higiene de los casos en los que se precise.

8. Creación de una App de mejora de la comunicación: dentro de las actividades encaminadas a dar respuesta a las necesidades de las personas beneficiarias del proyecto, se está desarrollando una aplicación para dispositivos móviles que facilite la comunicación entre los profesionales de la entidad y los familiares de aquellas personas que precisan supervisión, además de esta iniciativa de innovación tecnológica en el territorio que permite la comunicación de manera sincrónica y asincrónica facilitando así, a las familias que residen fuera de su entorno, el acceso a la vida cotidiana de la persona beneficiaria; facilitándole la información sobre 
la gestión de la toma de la medicación, nutricional, de actividades de la vida diaria, de relaciones sociales, incluso, comunicación directa con la persona usuaria, facilitando el acceso al control y seguimiento de su estado de salud.

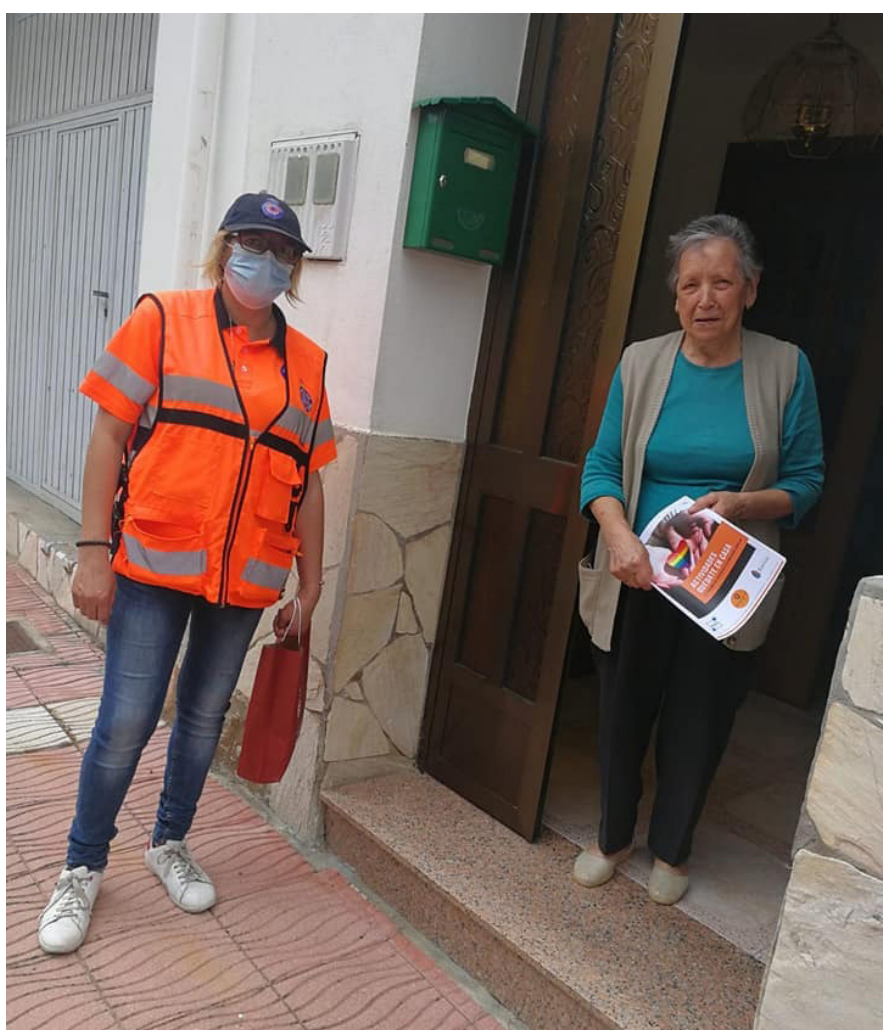

Figura n. ${ }^{\circ}$ 4. Fotografía que muestra como una mujer que pertenece a protección civil entrega las actividades de estimulación cognitiva a una beneficiaria del proyecto.

9. Creación de un manual sobre la historia de cada localidad: dentro de su objetivo de mejora de vida de las personas y de fijación de población, el proyecto se plantea realizar actividades que recuperen y registren el patrimonio inmaterial de las localidades donde realizan las intervenciones. Es decir, recuperación de tradiciones o expresiones vivas heredadas de los antepasados y transmitidas a las personas que residen actualmente en el medio rural tales como tradiciones orales, artes del espectáculo, usos sociales, rituales, actos festivos, conocimientos y prácticas relativas a la naturaleza y saberes y técnicas vinculadas a la artesanía tradicional; 
MARTA SOLÓRZANO GARCÍA, ANA PILAR RODRÍGUEZ GUZMÁN Y SARA REAL CASTELAO CONSTRUIR EL TERRITORIO DESDE LA ECONOMÍA SOCIAL Y SOLIDARIA Y EL FEMINISMO: PROYECTO «QUÉDATE»

utilizando estas vivencias como terapia emocional y musical para las personas beneficiarias directas del programa, entendiendo que el desarrollo de las tradiciones sirve para satisfacer necesidades humanas vitales tanto individuales como sociales. Para lograr este objetivo, desde el año 2019 se ha iniciado la elaboración de un manual con la historia, costumbres y tradiciones de cada una de las 17 localizaciones.

10. Terapia musical con elementos tradicionales: dentro de esta actuación trabajará mediante técnicas y método terapéuticos diferentes artes del espectáculo que van desde la música vocal o instrumental, la danza, el teatro musical, la pantomima y otras formas de expresión. Abarcando todas las expresiones culturales que reflejan la creatividad humana, con el fin de desarrollar en el futuro programas de intervenciones específicas para promover la salud y conseguir un adecuado envejecimiento, ya que se producen mejoras notables en los tres niveles de salud de las personas (psíquico, físico y social), consiguiendo una rehabilitación gradual en el ámbito de la comunicación, la relajación, la expresión, la movilidad y el nivel cognitivo.

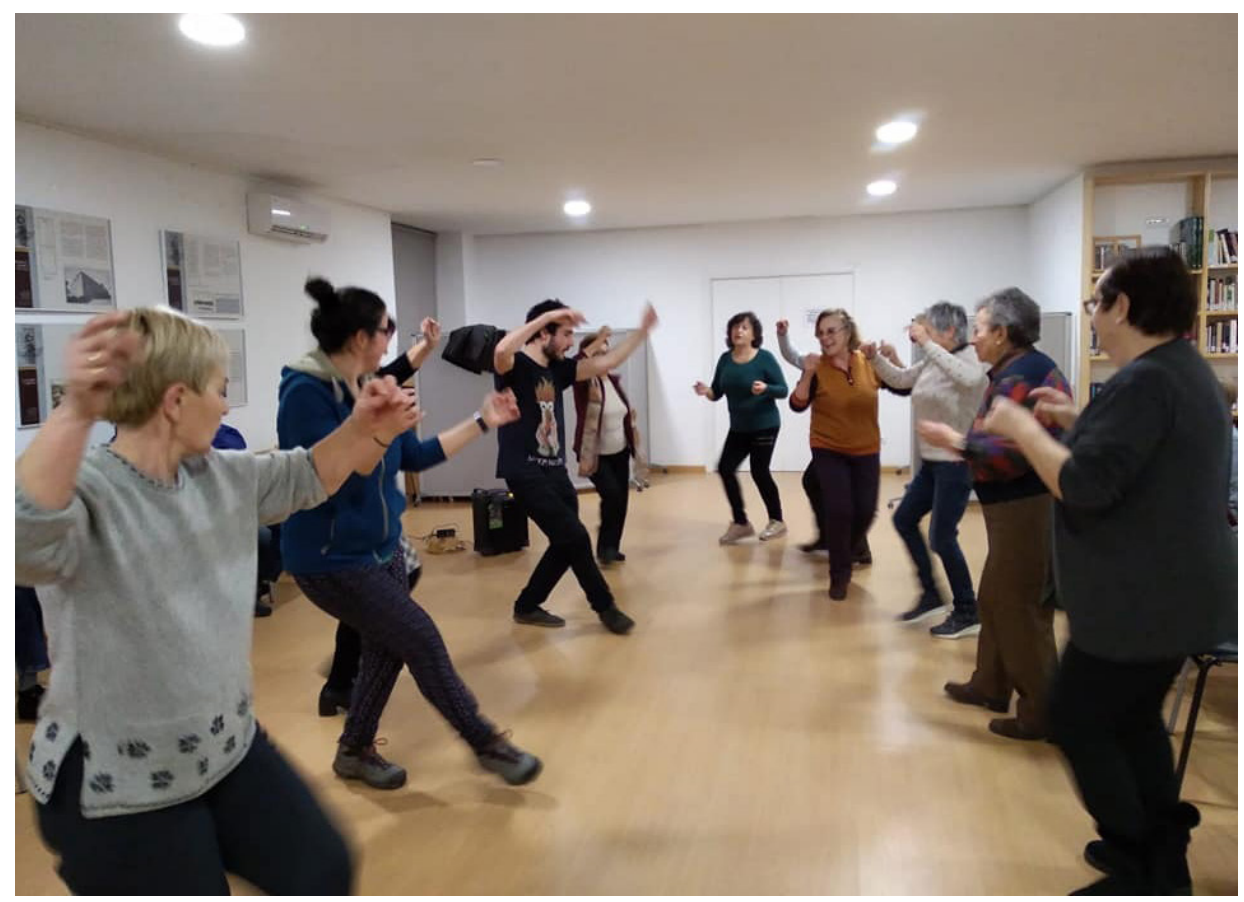

Figura n. ${ }^{\circ}$. Fotografía tomada durante un taller de terapia musical en el que las beneficiarias enseñan bailes tradicionales al grupo. 
MARTA SOLÓRZANO GARCÍA, ANA PILAR RODRÍGUEZ GUZMÁN Y SARA REAL CASTELAO CONSTRUIR EL TERRITORIO DESDE LA ECONOMÍA SOCIAL Y SOLIDARIA Y EL FEMINISMO: PROYECTO «QUÉDATE»

11. Coordinación Multidisciplinar: para poder desarrollar las actuaciones aquí expuestas es imprescindible crear espacios y tiempos para la coordinación entre todos los agentes claves que intervienen en el proyecto en cada una de las ubicaciones. Con este fin los agentes sociales y sanitarios en todas las localidades de intervención tienen reuniones periódicas para informar, contrastar las distintas fuentes de cada una de las áreas y realizar las derivaciones oportunas de las personas beneficiarias a las distintas actuaciones descritas en este proyecto.

12. Convenios de Colaboración: Con el fin de ampliar a otras localidades el proyecto y de mantener e impulsar las actividades realizadas en las localidades en las que ya se encuentra implantado, la última actuación aquí planteada es el establecimiento de convenios de colaboración con otras asociaciones y entidades bercianas invitándolas a implicarse y participar en el desarrollo de acciones del proyecto "Quédate». Estas colaboraciones son imprescindibles, siendo el establecimiento de alianzas entre instituciones de distinto carácter y nivel administrativo una de las claves para el mantenimiento del proyecto.

En la actualidad, tras 5 años de desarrollo desde su implantación, el proyecto ya plantea además del objetivo de la fijación de población, la atracción de personas que vayan a vivir a las zonas para ampliar los servicios. Con este fin, desde AFA Bierzo se han ofertado talleres de formación para mujeres emprendedoras en colaboración con la asociación de cibervoluntarios y el apoyo de instituciones locales como el Ayuntamiento de Ponferrada, sobre marketing digital para emprendedoras y uso de plataformas virtuales. Estos talleres de carácter gratuito han contado con la participación de 20 mujeres con iniciativas de emprendimiento en diversas áreas de actividad (artesanía, textil, apicultura, restauración, psicología, educación, turismo, fotografía o gestión cultural, entre otros), que han adquirido competencias digitales para impulsar sus actividades en la red. La fotografía 6 muestra una imagen de una de las sesiones de estos talleres impartidos en las instalaciones de AFA Bierzo. 


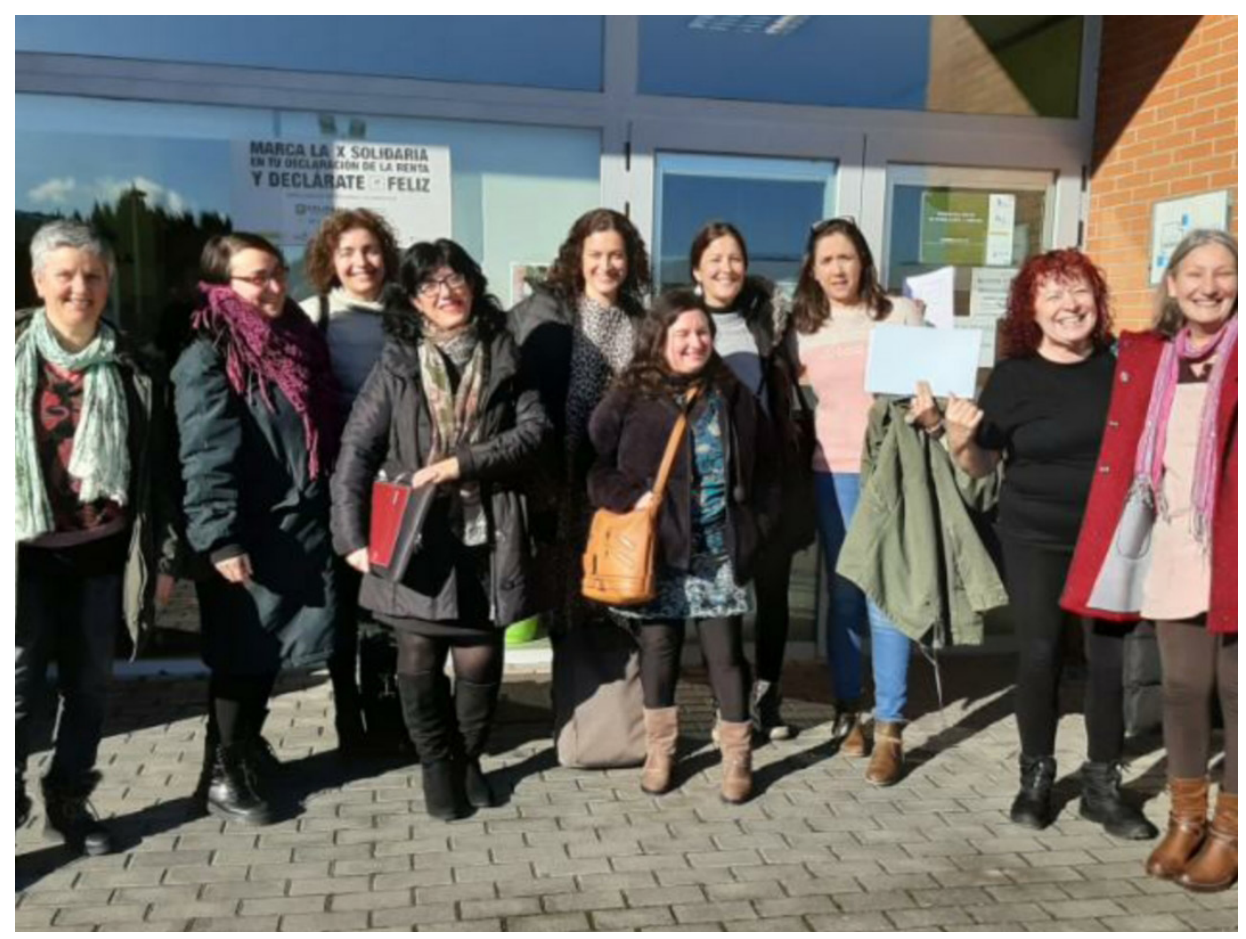

Figura n. ${ }^{\circ}$ 6. Fotografía realizada al término el taller de formación sobre marketing digital para mujeres emprendedoras.

La posibilidad de contacto y conocimiento mutuo durante la formación ha permitido que 11 de las 20 mujeres participantes hayan iniciado los trámites de consultoría y formación para crear una sociedad cooperativa gracias al asesoramiento de la asociación Cooperactivas, entidad que aporta información, formación y asesoramiento en la creación de empresas, profesionales y asociaciones bajo el modelo de la economía social y solidaria.

Estas 11 mujeres tienen el propósito de crear una cartera de servicios que se ofrezcan en el medio rural, a partir de sus propias experiencias empresariales y competencias personales y serán parte del proyecto «Quédate» que las apoyará en su formación y en el contacto con otras entidades que les asesoren en cada etapa específica del proceso de emprendimiento con bases en la economía social y solidaria y el feminismo.

El desarrollo realizado por el proyecto descrito está dando respuesta a las necesidades de las personas del entorno rural, incluyendo en estas iniciativas a grupos sociales que son excluidos de otros desarrollos y actividades como son las personas mayores y mujeres, en particular, y las personas del medio rural en 
MARTA SOLÓRZANO GARCÍA, ANA PILAR RODRÍGUEZ GUZMÁN Y SARA REAL CASTELAO CONSTRUIR EL TERRITORIO DESDE LA ECONOMÍA SOCIAL Y SOLIDARIA Y EL FEMINISMO: PROYECTO «QUÉDATE»

general; apostando por nuevas iniciativas que permitan la transformación social del territorio rural y que protejan y conserven las comunidades y su entorno, fijando población y preservando el patrimonio inmaterial. Por ello, tal y como se detalla en la tabla 2, este proyecto promueve con el desarrollo de sus objetivos los principios coincidentes con la economía social y solidaria y el feminismo detallados en apartados precedentes.

TABLA 2. RELACIÓN ENTRE OBJETIVOS COINCIDENTES DE LA ECONOMÍA SOCIAL Y SOLIDARIA Y FEMINISMO Y EL PROYECTO QUÉDATE

\begin{tabular}{|c|c|}
\hline $\begin{array}{l}\text { OBJETIVOS DE LA ECONOMÍA SOCIAL } \\
\text { Y SOLIDARIA Y FEMINISMO }\end{array}$ & $\begin{array}{l}\text { ACTUACIONES DESARROLLADAS POR EL PROYECTO } \\
\text { QUÉDATE }\end{array}$ \\
\hline $\begin{array}{l}\text { Dar respuesta a necesidades } \\
\text { humanas. }\end{array}$ & $\begin{array}{l}\text { - Detección de necesidades sociales, sanitarias, } \\
\text { funcionales y psicológicas. } \\
\text { - Detección de síntomas de deterioro cognitivo e } \\
\text { intervención. } \\
\text { - Creación de empleo para personas del medio } \\
\text { rural en su mayoría mujeres. }\end{array}$ \\
\hline $\begin{array}{l}\text { Reconstruir jerarquías económicas } \\
\text { en las que no se excluyan a } \\
\text { grupos sociales ni se apliquen } \\
\text { prácticas opresivas. }\end{array}$ & $\begin{array}{l}\text { - Apoyo y asesoramiento en nuevos } \\
\text { emprendimientos para mujeres. } \\
\text { - } \text { Redes de colaboración para impartir formación } \\
\text { y dar asesoramiento de manera gratuita. } \\
\text { - Creación de alianzas con instituciones públicas } \\
\text { y privadas que fomenten el desarrollo territorial. }\end{array}$ \\
\hline $\begin{array}{l}\text { Innovación y transformación } \\
\text { social. }\end{array}$ & $\begin{array}{l}\text { - Desarrollo de aplicaciones para dispositivos } \\
\text { móviles que favorezcan la comunicación. } \\
\text { _ Vinculación intergeneracional. }\end{array}$ \\
\hline $\begin{array}{l}\text { Protección y conservación de } \\
\text { las comunidades y del medio } \\
\text { ambiente. }\end{array}$ & 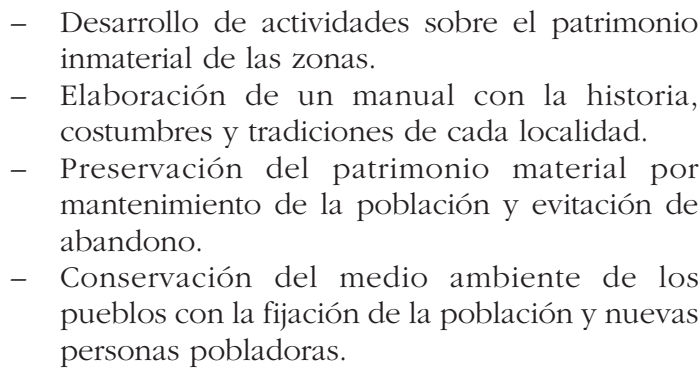 \\
\hline
\end{tabular}

Además del desarrollo de estos objetivos en el proyecto que han permitido la construcción del territorio en el medio rural, otra clave del éxito es la red de colaboraciones institucionales públicas y privadas que han participado de manera solidaria en el proyecto y que han creado un sistema de gobernanza institucional 
MARTA SOLÓRZANO GARCÍA, ANA PILAR RODRÍGUEZ GUZMÁN Y SARA REAL CASTELAO CONSTRUIR EL TERRITORIO DESDE LA ECONOMÍA SOCIAL Y SOLIDARIA Y EL FEMINISMO: PROYECTO «QUÉDATE»

que permite la articulación de recursos públicos y privados con un fin común, el desarrollo del territorio de un modo sostenible.

\section{CONClUSIONES Y PROPUESTAS DE FUTURO}

En el presente artículo se ha planteado una descripción de la sociodemografía de las zonas rurales de la provincia de León, detallando la situación particular de la Comarca de El Bierzo, que ha sufrido un proceso de despoblación tardío marcado por el cierre de la actividad minera del carbón.

Estos entornos han sido excluidos de los proyectos industriales urbanos que han marcado las inversiones económicas de las últimas décadas y que han provocado que las personas en edad activa se trasladen a otros entornos perdiendo población, servicios y, en último término, desapareciendo como entornos en los que vivir y convivir más allá de las vacaciones o fines de semana.

Como alternativa a estos modelos de desarrollo económico, se han descrito los modelos que plantea la economía social y solidaria en los puntos coincidentes de este modelo con el feminismo desde los que se propicia una nueva construcción del territorio en la que se pone a las personas en el centro y se tiene en cuenta el medioambiente y la comunidad. La economía social y solidaria, además de ofrecer principios y enfoques alternativos al funcionamiento de la economía capitalista, propone iniciativas prácticas en todos los subsistemas empresariales (financiación, producción, comercialización y consumo), colocando a las personas y, en general, la sostenibilidad de la vida en el centro y el propósito de su actividad. En este sentido, proponemos la economía social y solidaria como una realidad socioeconómica dentro de la que construir las posibles experiencias empresariales con las que crear riqueza en el territorio analizado con base en principios conformes a la solidaridad, la confianza, la cooperación y el trabajo colectivo. Proyectos en los que la gente y el bienestar individual y colectivo tengan prioridad sobre la rentabilidad financiera.

Como ejemplo y referente de este tipo de proyectos en el tercer apartado se ha realizado un análisis del proyecto "Quédate», proyecto desarrollado desde AFA Bierzo cuyo objetivo es la mejora de la calidad de vida de las personas que viven en el entorno rural mediante la atención integral de sus necesidades, permitiendo que las personas no se vean en la necesidad de abandonar los entornos en los que han vivido y con los que están vinculados.

Este proyecto que ya cuenta con 5 años de desarrollo ya ha logrado impactos tan destacables como la atención directa a 845 personas y sus familias, la contratación de 18 personas que ofrecen los servicios en el medio rural, el desarrollo de actividades para la preservación del patrimonio inmaterial o el impulso de una cooperativa como empresa social interdisciplinar que pretende dar servicios a estas zonas. 
MARTA SOLÓRZANO GARCÍA, ANA PILAR RODRÍGUEZ GUZMÁN Y SARA REAL CASTELAO CONSTRUIR EL TERRITORIO DESDE LA ECONOMÍA SOCIAL Y SOLIDARIA Y EL FEMINISMO: PROYECTO "QUÉDATE"

Además de la buena gestión y trabajo realizado por la entidad AFA Bierzo, se destacan las colaboraciones de entidades públicas y privadas que han permitido desarrollar los objetivos. Este proyecto ha contado con el apoyo de administraciones locales, provinciales, y asociaciones que han aportado mediante financiación y recursos materiales y humanos los apoyos necesarios para lograr los impactos comentados.

Como conclusión, cabe resaltar, la importancia de iniciativas como el proyecto "Quédate» en zonas rurales despobladas como las de la Comarca de El Bierzo, en las que el envejecimiento de la población, pasa de ser un indicador visto como problema en los análisis estadísticos a una oportunidad para mantener los entornos rurales, dando respuesta a esta población con servicios que crean empleo y atraen a otros emprendimientos, generando redes de cooperación y medios de vida para las personas cuya elección es mantenerse en estos entornos.

\section{REFERENCIAS BIBLIOGRÁFICAS}

BOE-Boletín Oficial del Estado. (2009). Orden INT/1088/2009, de 16 de abril. Martes 5 de mayo de 2009. N. ${ }^{\circ}$ 109. https://www.boe.es/boe/dias/2009/05/05/pdfs/BOES-2009-109.pdf

BOE-Boletín Oficial del Estado. (2020). Real Decreto 463/2020, de 14 de Marzo. Sábado 14 de marzo de 2020. N. ${ }^{\circ}$ 67. https://www.boe.es/eli/es/rd/2020/03/14/463/dof/spa/pdf

Caballero, P., Delgado, J. M., Martínez, L. C. (2012). La evolución demográfica de Castilla y León. Una trayectoria que refleja los rasgos y manifiesta las contradicciones del modelo español. Valladolid: Consejo Económico y Social de Castilla y León. Disponible en: http://uvadoc.uva.es/handle/10324/9079

Calatrava-Requena, J. (1997). Importancia de la integración de la mujer en los procesos de desarrollo rural. En VV. AA. (cords.), La Mujer: clave del Desarrollo Rural (pp. 19-38). Málaga: Junta de Andalucía. https://www.researchgate.net/publication/262049026_Importancia_de_la_integracion_de_la_mujer_en_los_procesos_de_desarrollo_rural

Camarero, L., Sampedro, R. (2008). ¿Por qué se van las mujeres? El continuum de movilidad como hipótesis explicativa de la masculinización rural. Revista Española de Investigaciones Sociales, 124, pp. 73-105. http://www.reis.cis.es/REIS/PDF/ REIS_124_031222873178255.pdf

CEP CMAP. (2002). Déclaration finale commune des organisations européennes de l'Économie Sociale. CEP-CMAF, 20 June.

Carmona García, F. J. (2013). Análisis territorial de los efectos de los programas de desarrollo rural LEADER+ y PRODER II en Castilla-La Mancha. [Tesis elaborada para obtener el título de doctor ingeniería agrónoma]. Albacete: Universidad de Castilla-La Mancha.

Coragguio, J. L. (2011): Economía social y solidaria. En Acosta, Alberto y Esperanza Martínez (eds.), El trabajo antes que el capital. Quito: Serie Debate Constituyente, Abya-Yala.

Daros, G. S. (2007). Economía solidaria: Aspectos teóricos y experiencias. Unircoop, 5(1), pp. 9-27.

Díaz Méndez, C. (2005). Aproximaciones al arraigo y al desarraigo femenino en el medio rural: mujeres jóvenes en busca de una nueva identidad rural. Papers. 75, pp. 113-12. https://ddd.uab.cat/pub/papers/02102862n75/02102862n75p63.pdf 
MARTA SOLÓRZANO GARCÍA, ANA PILAR RODRÍGUEZ GUZMÁN Y SARA REAL CASTELAO

CONSTRUIR EL TERRITORIO DESDE LA ECONOMÍA SOCIAL Y SOLIDARIA Y EL FEMINISMO: PROYECTO "QUÉDATE»

Guerra, P. (2013). Las legislaciones sobre economía social y solidaria en américa latina entre la autogestión y la visión sectorial. Revista de la Facultad de Derecho, 33, pp. 73-94.

Guerra, P. (2011). ¿Cómo denominar a las experiencias económicas solidarias basadas en el trabajo? Diálogo entre académicos latinoamericanos acerca de la polémica conceptual. Otra Economía, 1(1): pp. 21-27.

Hoinle, B., Rothfuss, R., Gotto, D. (2013). Empoderamiento espacial de las mujeres mediante la Economía Solidaria. Cuadernos de Desarrollo Rural, 10(72), pp. 117-139. http:// www.scielo.org.co/pdf/cudr/v10n72/v10n72a07.pdf

INE-Instituto Nacional de Estadística. (2020a). Indicadores demográficos básicos. https:// www.ine.es/dyngs/INEbase/es/operacion.htm?c=Estadistica_C\&cid=1254736177003\& menu=ultiDatos\&idp $=1254735573002$

INE-Instituto Nacional de Estadística. (2020b). Indicadores de la Agenda 2030 para el Desarrollo Sostenible. Objetivo 5. Lograr la igualdad de género y empoderar a todas las mujeres y las niñas. https://www.ine.es/dynt3/ODS/es/objetivo.htm?id=4977

Larrañaga, M. (2014). «Mirando la enseñanza de la Economía desde el feminismo». Dossieres EsF, 15, pp. 30-33. http://www.ecosfron.org/wp-content/uploads/Dossier-15-EsF.pdf

Martínez, A., Álvarez, S. (2008): «La economía crítica y solidaria: perspectivas teóricas y experiencias para la construcción de una economía alternativa», En: La situación del mundo 2008. Innovaciones para una economía sostenible. Informe anual del Worldwatch Institute sobre el Progreso hace una Sociedad Sostenible (371-486). Barcelona: CIP-Ecosocial e Icaria.

Matthaei, J. (2010). «Más allá del hombre Económico: Crisis Económica, Economía Feminista, y la Economía Solidaria». En: Revista Venezolana de Economía Social. 10(19), pp. 65-80. http://www.saber.ula.ve/bitstream/handle/123456789/32073/articulo5.pdf;jsessionid= CA510F1105F6533D94076C946A3CBD52?sequence $=1$

Monzón, J. L., Chaves, R. (2012). La economía social en la Unión Europea. Bruselas: Comité Económico y Social. Nieto Masot, A., Gurría Gascón, J. L. (2010). El modelo rural y el impacto de los programas LEADER y PRODER en Extremadura (propuesta metodológica). En: Scripta Nova. Revista Electrónica de Geografía y Ciencias Sociales, XIV(340). http://www.ub.edu/geocrit/sn/sn-340.htm

Osorio Cabrera, M. D. (2014) Economía Solidaria e interdependencia: aportes desde perspectivas feministas. Quaderns de Psicologia. International Journal of Psycholog, 16(1), pp. 153-165. https://www.raco.cat/index.php/QuadernsPsicologia/article/view/10.5 565-rev-psicologia.1198

Pérez de Mendiguren, J. C., Etxezarreta, E. (2015). Sobre el concepto de Economía social y solidaria: aproximaciones desde Europa y América Latina. Revista de economía mundial, 40, pp. 123-143.

Ribas Bonet, M. A., Sajardo Moreno A. (2005). La diferente participación laboral de las mujeres entre las cooperativas y las sociedades laborales. CIRIEC-España. Revista de economía pública, social y cooperativa, 52, pp. 267-278. https://www.redalyc.org/ pdf/174/17405214.pdf

Sánchez Muñoz, M. ${ }^{a}$ J. (1999): Los programas de desarrollo rural en la provincia de León. Polígonos, Revista de Geografía, 8, pp. 151-176.

Senent Vidal, M. J. (2011). ¿Cómo pueden aprovechar las cooperativas el talento de las mujeres?.. Responsabilidad social empresarial e igualdad real. REVESCO, 105, pp. 57-84. http://repositori.uji.es/xmlui/handle/10234/148105 
MARTA SOLÓRZANO GARCÍA, ANA PILAR RODRÍGUEZ GUZMÁN Y SARA REAL CASTELAO CONSTRUIR EL TERRITORIO DESDE LA ECONOMÍA SOCIAL Y SOLIDARIA Y EL FEMINISMO: PROYECTO “QUÉDATE»

Verdugo Matés, R. Pérez Fra, M. López Iglesias, E. (2004). La contribución de los programas LEADER y PRODER a la diversificación de actividades en el medio rural; análisis para Galicia. En VV. AA. (Coords.), Agricultura, alimentación y espacio rural en transición. Santiago de Compostela: Asociación Española de Economía Agraria, pp. 1-19. https://www.researchgate.net/publication/266022268_La_contribucion_de_los_programas_LEADER_y_PRODER_a_la_diversificacion_de_actividades_en_el_medio_rural_analisis_para_Galicia?channel=doi\&linkId=5423208d0cf26120b7a6bb74\&showFullt ext=true 
